\title{
Electrogenerated networks from poly [4-(diphenylamino)benzyl methacrylate] and their electrochromic properties
}

\author{
O. I. Negru*, L. Vacareanu, M. Grigoras \\ 'P. Poni' Institute of Macromolecular Chemistry, Electroactive Polymers Department, 41A Gr. Ghica Voda alley, \\ Iasi-700487, Romania
}

Received 24 February 2014; accepted in revised form 28 April 2014

\begin{abstract}
Poly[4-(diphenylamino)benzyl methacrylate] with well-defined molecular weight and low polydispersity was prepared by atom transfer radical polymerization (ATRP) using 4-(diphenylamino) benzyl 2-bromo-2-methyl-propanoate as initiator and $\mathrm{CuBr} / 2,2^{\prime}$-bipyridine as catalytic complex. Electrochemical behavior and optical properties of the polymers were investigated by cyclic voltammetry and UV-Vis and fluorescence spectroscopy. Cyclic votammetric studies revealed that the redox processes were accompanied by dimerization of triphenylamine pendant groups. The initial polymer was postmodified, in solution or bulk, by electrochemical oxidation leading to a crosslinked and insoluble network with electrochromic properties, accompanied by strong color changes with high coloration efficiency. The crosslinking reaction took place between triphenylamine groups through para free positions leading to tetraphenylbenzidine bridges. The structure of polymers was confirmed by Fourier transform infrared (FT-IR) spectroscopy and ${ }^{1} \mathrm{H}$ and ${ }^{13} \mathrm{C}$-nuclear magnetic resonance spectroscopy. Morphology studies of the cross-linked film have evidenced a smooth and continuous aspect without any pinholes or defects.
\end{abstract}

Keywords: polymer synthesis, triphenylamine-based polymers, crosslinking, electrochromic networks

\section{Introduction}

Conjugated polymers have been extensively investigated in the last decades and continue to attract scientific interest due to their wide range of applications. Among the large variety of conjugated polymers, triphenylamine-based oligomers and polymers have received much attention because they have good hole-transporting properties, high lightemitting efficiencies, photoconductivity and photorefractivity, large two-photon absorption crosssection, being attractive materials for optoelectronic applications [1-3]. Responsible for all these properties is triphenylamine, a well-known molecule that possesses interesting functions such as redox activity, fluorescence, high oxidability of nitro- gen center and good hole-transporting properties via radical-cation species [4]. Thus, oligomers and polymers containing triphenylamine group in the main or side chain have found applications as photoconducting materials in xerography, organic fieldeffect transistors, photorefractive systems, light emitting diodes [5-7], solar cells [8,9] or electrochromic materials $[10,11]$.

Electrochromic materials have ability to change reversible their absorption and transmittance upon electrochemical oxidation or reduction. For electrochromic applications these materials have to possess good film-forming properties, long-term stability, high coloration efficiency and fast switching of color. To increase the long-term stability an efficient

\footnotetext{
${ }^{*}$ Corresponding author, e-mail: irimia.oana@icmpp.ro

(C) BME-PT
} 
route is to use cross-linked materials. Electrochromic networks can be obtained as films with fine control of the layer thickness from vinyl polymers containing carbazole or triphenylamine substituents by anodic oxidation [12-14]. Generally, vinyl polymers that contain pendant chromophore groups (carbazole, triphenylamine, etc.) have greater solubility than rigid-rod conjugated polymers, facilitating thus their processing as thin films from solution. In the class of carbazole-based polymers, an important place is taken by poly (N-vinylcarbazole) (PVK) because it is easily synthesized and soluble in common organic solvents [15]. The controlled radical polymerizations of N-vinyl carbazole (VK) monomers are considered to be difficult because radical precursors are highly reactive due to the nature and strong electron donating pendant groups $[16,17]$. Nevertheless, several attempts to synthesize PVK using various controlled radical polymerization systems have been reported in the literature. Polymerization via reversible addition-fragmentation chain transfer (RAFT) can be only readily mediated using xanthates or dithiocarbamate as the chains transfer agent $[16,18-21]$ or nitroxide-mediated polymerization (NMP) [22] and by atom transfer radical polymerization (ATRP) [23, 24].

Several attempts for synthesis of vinyl polymers having triphenylamine as pendant groups, using controlled radical polymerization (NMP [25-28] and RAFT [29-32]) or living anionic route [33-40] have been recently reported. However, the controlled radical polymerization of triphenylamine-based (meth) acrylate monomers was less studied until now, only a paper revealing the group transfer polymerization of 4-(dimethylamino)benzyl methacrylate was published [41]. As a continuation of our previous studies regarding controlled radical polymerization of arylamine-based vinyl monomers [19, 42, 43], in this paper we have reported the synthesis and characterization of poly [4-(diphenylamino) benzyl methacrylate] employing the atom transfer radical polymerization method. This polymer was used in the next step in order to obtain electrochromic networks by electrochemical crosslinking of triphenylamine pendant sites.

\section{Experimental}

\subsection{Materials}

Methacryloyl chloride (97\%), triethylamine (99,5\%), copper (I) bromide ( $\mathrm{CuBr}, 99,99 \%), 2,2$-bipyridine (bpy) (98\%) and tetrabutylammonium tetrafluoroborate $\left(\mathrm{TBABF}_{4}\right)$ were purchased from Aldrich (Steinheim, Germany) and used without further purification. Solvents (Aldrich) were dried by usual methods or used as received. 4-(diphenylamino) benzyl alcohol and 4-(diphenylamino) benzyl 2-bromo-2methylpropanoate, were synthesized according to the reported methods [42].

\subsection{Measurements}

The infrared spectra of the polymers were recorded on FT-IR Bruker Vertex 70 Spectrophotometer in transmission mode using $\mathrm{KBr}$ pellets (Ettlingen, Germany). UV-Vis absorption and fluorescence spectra of polymers were recorded with a Specord 200 spectrophotometer (Analytik Jena AG, Jena, Germany) and Perkin Elmer LS 55 apparatus (United Kingdom), respectively, by using diluted polymer solutions and very thin films deposited on quartz plates by drop-cast technique. ${ }^{1} \mathrm{H}$ and ${ }^{13} \mathrm{C}-\mathrm{NMR}$ spectra were recorded on a Bruker NMR spectrometer, Avance DRX $400 \mathrm{MHz}$ (Rheinstetten, Germany), using deuterated chloroform $\left(\mathrm{CDCl}_{3}\right)$ and tetramethylsilane as an internal standard. Gel permeation chromatography (GPC) analyses were carried out on PL-EMD 950 Evaporative light Detector instrument using chloroform $\left(\mathrm{CHCl}_{3}\right)$ as an eluent phase and standard polystyrene sample for calibration. Samples were filtered through $0.45 \mu \mathrm{m}$ syringe. The surface investigation was performed using atomic force microscopy (AFM) solver PRO-M (NT-MDT, Russia). Thin film of the cross-linked polymer was deposited upon ITO coated. Differential scanning calorimetry (DSC) measurements were conducted on a Pyris Diamond DSC, Perkin Elmer (USA), in nitrogen with a heating and cooling rate of $10^{\circ} \mathrm{C} / \mathrm{min}$. The glass transition temperatures $\left(T_{\mathrm{g}}\right)$ were determined from the second heating run.

Electrochemical studies were carried out with a Bioanalytical System, Potentiostat-Galvanostat (BASi 100B/W, SUA, Indiana, West Lafayette). All the experiments were performed in a one-compartment cell using a standard three-electrode cell arrangement with a working platinum electrode, an auxiliary electrode (platinum wire), and a reference electrode (consisted of a silver wire coated with $\mathrm{AgCl}$ ). Before each experiment, the Pt working electrode was cleaned by polishing it successively with 0.3 and $0.05 \mu \mathrm{m} \mathrm{Al}_{2} \mathrm{O}_{3}$ slurry on emery paper to a mirror finish, and then washed with methanol and bi-dis- 
tilled water. The electrochemical studies were carried out both in solution and film deposited on platinum electrode and tetrabutylammonium tetrafluoroborate $\left(\mathrm{TBABF}_{4}\right)$ as supporting electrolyte.

Electro-optical properties were investigated using an indium tin oxide (ITO, Adrich Sigma Aldrich with an active area of $1.1 \mathrm{~cm} \times 0.8 \mathrm{~cm}$ ) electrode as well as a platinum wire as counter electrode and an $\mathrm{AgCl}$ reference electrode. A film of the cross-linked polymer was deposited upon ITO coated glass electrode by electrochemical polymerization using a solution of polymer in acetonitrile/toluene (1:1) and $\mathrm{TBABF}_{4}$ as electrolyte. The film was prepared by sweeping the potential between 0 and $+1.8 \mathrm{~V}$ for 14 scan cycles and after deposition, the ITO/polymer film was rinsed with distilled water and further used as working electrode in a standard spectroelectrochemical cell (a quartz cuvette of $1 \mathrm{~cm} \times 1 \mathrm{~cm}$ dimensions) filled with supporting electrolyte $\left(\mathrm{TBABF}_{4}\right.$, solution $0.1 \mathrm{M}$ in acetonitrile/toluene, $1: 1)$. The electrodes were connected to a BASi PotentiostatGalvanostat and spectroelectrochemical spectra were recorded using an SEC-2000-UV/VIS-type spectrophotometer (Tokyo, Japan).

\subsection{Synthesis of 4-(diphenylamino) benzyl methacrylate}

Monomer was prepared according to the modified method described in the literature [44]. To a mixture of 4-(diphenylamino) benzyl alcohol (7.00 g, $25.42 \mathrm{mmol}$ ) and triethylamine $(3.08 \mathrm{~g}, 4.05 \mathrm{~mL}$, $30.5 \mathrm{mmol})$ in dry toluene $(150 \mathrm{~mL})$, methacryloyl chloride (3.18 g, $2.95 \mathrm{~mL}, 30.5 \mathrm{mmol})$ was slowly added at $0{ }^{\circ} \mathrm{C}$ under argon atmosphere. The reaction mixture was then stirred for $24 \mathrm{~h}$, at room temperature. The $\mathrm{Et}_{3} \mathrm{~N} \cdot \mathrm{HCl}$ was separated by filtration and the toluene solution was washed successively with $\mathrm{Na}_{2} \mathrm{CO}_{3}$ solution, water and finally dried on $\mathrm{CaCl}_{2}$. After toluene evaporation in vacuum, monomer was purified by column chromatography (silica gel as stationary layer and a mixture of hexane: $\mathrm{CH}_{2} \mathrm{Cl}_{2}$ as eluent), giving $5.85 \mathrm{~g}(83 \%)$ as viscous oil. ${ }^{1} \mathrm{H}-\mathrm{NMR}$ $\left(\mathrm{CDCl}_{3}, \delta, \mathrm{ppm}\right): 1.96\left(\mathrm{~s}, 3 \mathrm{H},-\mathrm{CH}_{3}\right), 5.12(\mathrm{~s}, 2 \mathrm{H}$, $\left.-\mathrm{CH}_{2}-\mathrm{O}\right), 5.56$ and $6.14\left(\mathrm{~s}, 2 \mathrm{H},=\mathrm{CH}_{2}\right), 6.95-7.30$ (m, $14 \mathrm{H}$, aromatic protons). ${ }^{13} \mathrm{C}-\mathrm{NMR}\left(\mathrm{CDCl}_{3}, \delta\right.$, ppm): 18.35, 66.17, 122.99, 123.91, 124.72, 125.68, 129.40, 129.80, 136.30, 147.58, 167.30.

\subsection{Synthesis of poly [4-(diphenylamino) benzyl methacrylate]}

An example for ATRP polymerization was as follows (entry 2 in Table 1): In a two neck round bottom flask equipped with magnetic stirrer and nitrogen inlet-outlet, vacuumed and back-filled with nitrogen for several times, $\mathrm{CuBr}$ ( $8.48 \mathrm{mg}, 0.059 \mathrm{mmol}), 2,2-$ bipyridine (18.48 $\mathrm{mg}, 0.118 \mathrm{mmol})$, and the ATRP initiator $(25.1 \mathrm{mg}, 0.059 \mathrm{mmol})$ were added to a solution of monomer $(1.01 \mathrm{~g}, 2.95 \mathrm{mmol})$ in $3 \mathrm{~mL}$ toluene. The reaction mixture was degassed by nitrogen for $60 \mathrm{~min}$. The polymerization was carried out by immersing the flask into an oil bath thermostated at $103^{\circ} \mathrm{C}$, for 24 hours. Then, the reaction mixture was precipitated twice in a large amount of cold hexane from dichloromethane. The polymer was filtered and dried at $40^{\circ} \mathrm{C}$ in vacuum. Yield $=33.1 \%$. GPC measurements: $M_{\mathrm{n}}[\mathrm{g} / \mathrm{mol}]=5370, M_{\mathrm{w}} / M_{\mathrm{n}}=$ 1.13 .

\section{Results and discussion \\ 3.1. Synthesis}

The atom transfer radical polymerization of 4(diphenylamino)benzyl methacrylate monomer was

Table 1. Results and experimental conditions of polymerization of 4-(diphenylamino) benzyl methacrylate) using 4-(diphenylamino) benzyl 2-bromo-2-methylpropanoate as initiator in the presence of catalytic complex $\mathrm{CuBr} / \mathrm{bpy}$ at $103^{\circ} \mathrm{C}$

\begin{tabular}{|c|c|c|c|c|c|c|}
\hline Sample & {$[\text { Monomer }]_{0}:[\mathrm{I}]_{0}:[\mathrm{CuBr}]_{0}:[\mathrm{bpy}]_{0}$} & $\begin{array}{c}M_{n} \text { th. }^{(a)} \\
{[\mathrm{g} / \mathrm{mol}]}\end{array}$ & $\begin{array}{c}\mathbf{M}_{\mathbf{n}}^{(\mathbf{b})} \\
{[\mathrm{g} / \mathrm{mol}]}\end{array}$ & $\mathbf{M}_{\mathbf{w}} / \mathbf{M}_{\mathbf{n}}^{(\mathbf{b})}$ & $\begin{array}{c}\text { Yield } \\
{[\%]}\end{array}$ & $\begin{array}{c}\mathbf{T}_{\mathbf{g}} \\
{\left[{ }^{\circ} \mathbf{C}\right]}\end{array}$ \\
\hline P1 & $30: 1: 1: 2$ & 4330 & 4100 & 1.08 & 38.3 & 160 \\
\hline $\mathrm{P} 2$ & $50: 1: 1: 2$ & 6080 & 5370 & 1.13 & 33.1 & 161 \\
\hline P3 & $75: 1: 1: 2$ & 9400 & 8045 & 1.13 & 35.2 & 162 \\
\hline $\mathrm{P} 4$ & $150: 1: 1: 2$ & 9680 & 8920 & 1.18 & 18.6 & 162 \\
\hline
\end{tabular}

a) The theoretical number-average molecular weight is defined as follows:

$\bar{M}_{\mathrm{n}}($ theor. $)=\frac{[\text { Monomer }]_{0}}{[I]_{0}} \cdot M_{\text {Monomer }} \cdot$ Conv. $+M_{\mathrm{I}}$

where: $M_{\mathrm{I}}$ and $M_{\text {Monomer }}$ are the molecular weights of initiator (424) and of the monomer (343), and [Monomer $]_{0}$ and $[\mathrm{I}]_{0}$ are the initial concentrations of the monomer and I, respectively. Conversion was determined by gravimetry.

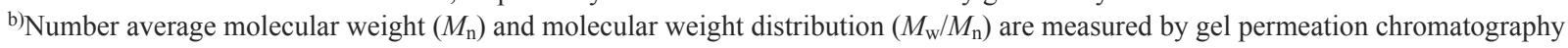
(GPC) using polystyrene as a standard in DMF. 
carried out in dry toluene at $103^{\circ} \mathrm{C}$ temperature, in the presence of 4-(diphenylamino) benzyl 2-bromo2-methylpropanoate as initiator and $\mathrm{CuBr} /$ bipyridyl as catalyst (Figure 1). This TPA-based initiator was previously used in ATRP polymerization of styrene to obtain triphenylamine end-functionalized polystyrenes with well-defined molecular weights and narrow polydispersities. The electrochemical and chemical oxidative polymerizations of these macromonomers led to soluble polytriphenylamine hairyrod polymers having oligostyrene segments as grafts in every hairy structural unit [42]. On the other hand, this initiator was also used as monomer for interfacial and microemulsion chemical oxidative polymerization in the presence of ammonium peroxodisulfate as the oxidizing agent, obtaining functional polytriphenylamines [43]. In this paper, 4-(diphenylamino) benzyl 2-bromo-2-methylpropanoate was used as an ATRP initiator in controlled radical polymerization of methacrylate monomer containing triphenylamine moiety, (4-(diphenylamino)benzyl methacrylate) (TPMA) to get macromonomers with controlled molecular weight and narrow polydispersity index (Table 1). At the end of the polymerization reaction, the polymers were precipitated in hexane. They are completely soluble in organic solvents such as THF, DMF and in chlorinated solvents and have a well-defined molecular weight and narrow polydispersity. The polymers were purified by dissolution in a small amount of THF to which was added few drops of ammonium hydroxide (to prevent oxidation of nitrogen of the triphenylamine unit) and precipitated in hexane.

The molecular weight of the polymers was controlled by varying the $[\text { monomer }]_{0} /[\text { initiator }]_{0}$ ratios and these ratios were fixed in the range of 30 to 150 , while all other experimental conditions were set to be the same. The $M_{\mathrm{n}}$ values proportionally increase by increasing the feed ratio and the polydispersity indices $\left(M_{\mathrm{w}} / M_{\mathrm{n}}\right)$ for all samples are less than 1.2. In all cases, the molecular weights measured by GPC in DMF, were lower than the theoreti-
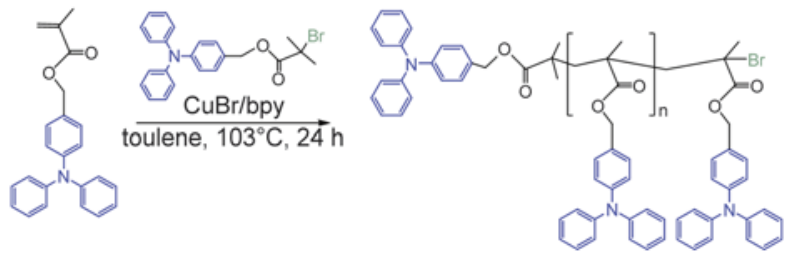

Figure 1. ATRP polymerization of 4-(diphenylamino)benzyl methacrylate cal values calculated from the monomer/initiator molar ratio and conversion of the monomer. The molecular weights obtained by conventional GPC using polystyrene calibration are just apparent values; moreover the conversion was approximated by gravimetry. The synthesized polymers have glass transition temperatures $\left(T_{\mathrm{g}}\right)$, determined by DSC at a heating rate of $10^{\circ} \mathrm{C} / \mathrm{min}$, in nitrogen atmosphere, after the second heating scan ranged between 160 $162^{\circ} \mathrm{C}$.

\subsection{FT-IR and NMR spectra}

The chemical structure of the polymer was proved by ${ }^{1} \mathrm{H}$ and ${ }^{13} \mathrm{C}$-NMR and FT-IR measurements. In Figure 2 is shown the ${ }^{1} \mathrm{H}-\mathrm{NMR}$ spectrum of poly [4-(diphenylamino) benzyl methacrylate] recorded in $\mathrm{CDCl}_{3}$. By comparing both the ${ }^{1} \mathrm{H}-\mathrm{NMR}$ spectrum for the monomer and polymer, in the last one it was observed the disappearance of the signals assigned to vinyl protons that in case of monomer spectra are located at 5.56 and $6.14 \mathrm{ppm}$ region. At the same time, new signals emerge around 0.8 to $2.2 \mathrm{ppm}$, associated with the protons of poly [4-(diphenylamino) benzyl methacrylate] backbone, while the signals located at $4.85 \mathrm{ppm}$ are assigned to methylene protons from the $-\mathrm{CH}_{2}-\mathrm{O}$ - polymer segments. All other peaks are readily assigned on the pendant triphenylamine groups. Due to the structural similarity of both initiator and monomer, it was not possible to calculate the polymer molecular weight by using ${ }^{1} \mathrm{H}-\mathrm{NMR}$ spectroscopy data. The ${ }^{13} \mathrm{C}$-NMR spectral analysis of polymer, recorded in $\mathrm{CDCl}_{3}$ shows the following signals: the region from 16.80 to $18.85 \mathrm{ppm}$ is assigned to signals of methyl carbons $(\mathrm{Ca})$, while the methylene carbon signals $(\mathrm{Cb})$ are visible in 22.66 to $30.32 \mathrm{ppm}$ region (Figure 3).

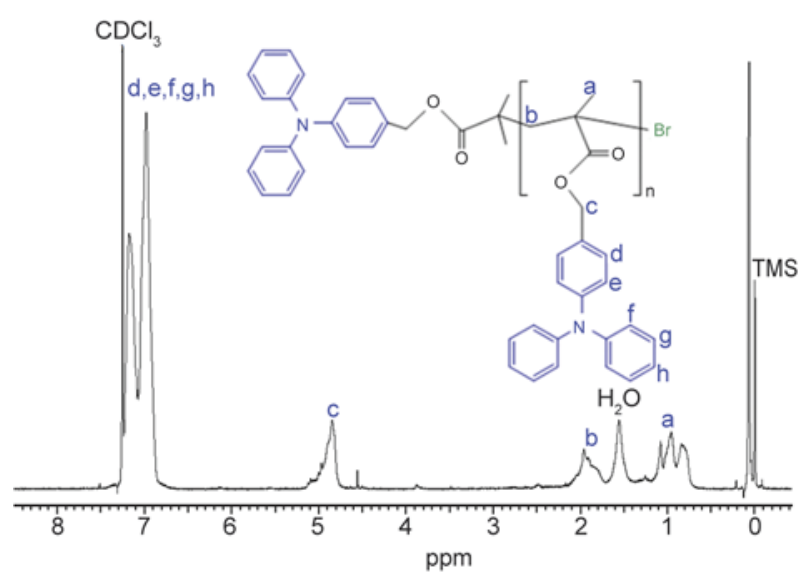

Figure 2. ${ }^{1} \mathrm{H}-\mathrm{NMR}\left(\mathrm{CDCl}_{3}\right)$ spectra of polymer 


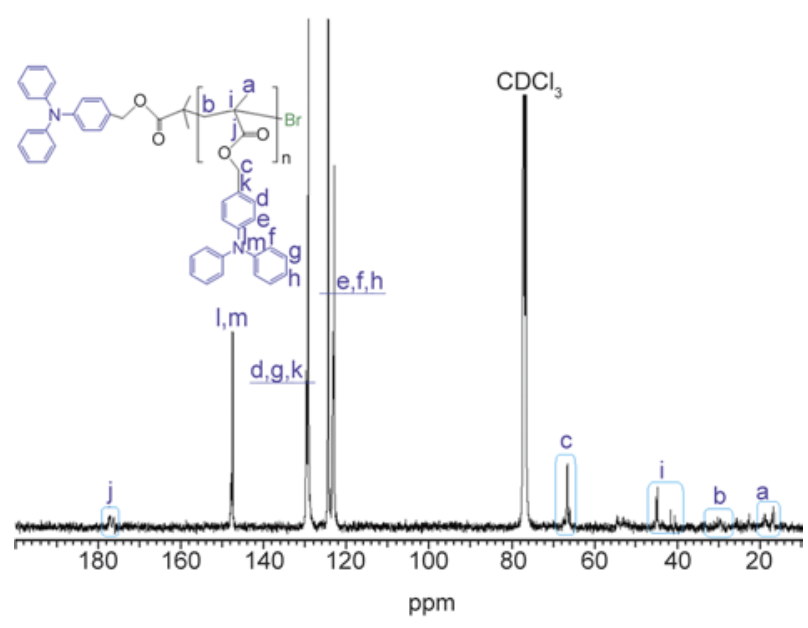

Figure 3. ${ }^{13} \mathrm{C}-\mathrm{NMR}\left(\mathrm{CDCl}_{3}\right)$ spectra of polymer

Quaternary carbons (Ci) show the signals in 40.69 to $44.18 \mathrm{ppm}$ region, and the methylene carbons $\mathrm{Cc}$ are located at $66.64 \mathrm{ppm}$. Aromatic carbons located in the region 123.02 to $124.48 \mathrm{ppm}$ are attributed to the carbon, $\mathrm{Cf}$ and $\mathrm{Ch}$, while $\mathrm{Cd}, \mathrm{Cg}, \mathrm{Ck}$ are located in the region 128.86 to $129.77 \mathrm{ppm}$, and carbons $\mathrm{Cl}$ and $\mathrm{Cm}$ are located at 147,95 and $147.60 \mathrm{ppm}$, respectively. The signals at 176.29 and $177.25 \mathrm{ppm}$ are assigned to the $\mathrm{Cj}$ carbonyl carbon.

In Figure 4 is shown the FT-IR spectrum of the polymer. The bands assigned to the $(\mathrm{H}-\mathrm{C}=)$ aromatic deformation vibrations are located at 3059 and $3033 \mathrm{~cm}^{-1}$. The $2961 \mathrm{~cm}^{-1}$ band is characteristic to deformation vibration of the aliphatic $(\mathrm{C}-\mathrm{H})$ linkages. The band at $1729 \mathrm{~cm}^{-1}$ is attributed to the valence vibration of $\mathrm{C}=\mathrm{O}$ bond while the bands located at 1140 and $1173 \mathrm{~cm}^{-1}$ are due to stretching vibrations of $\mathrm{C}-\mathrm{O}-\mathrm{C}$ bond. The bands at 1589 and $1492 \mathrm{~cm}^{-1}$ correspond to in-plane deformations of

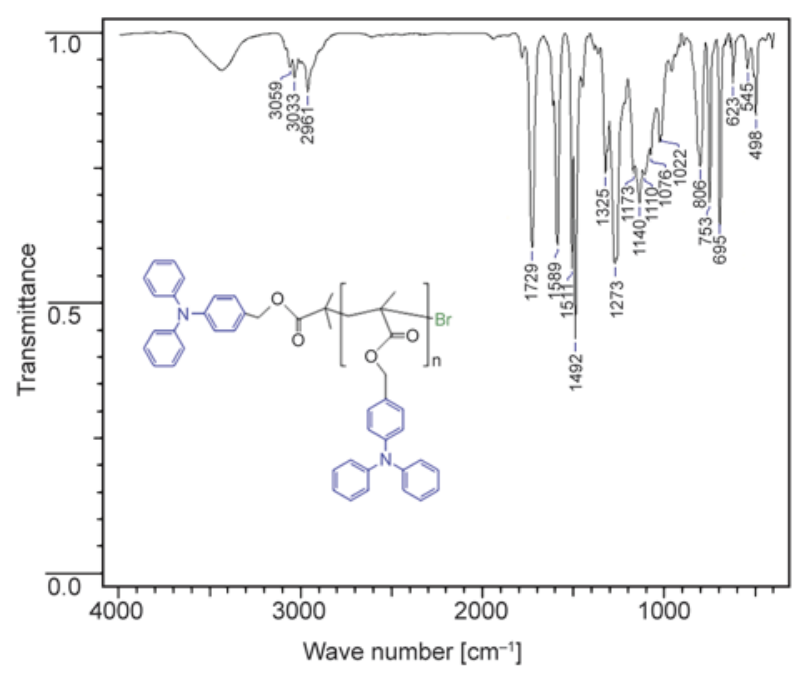

Figure 4. FT-IR spectrum $(\mathrm{KBr})$ of polymer

aromatic rings. The bands at 1110 and $1028 \mathrm{~cm}^{-1}$ are assigned to the deformation vibration of the methyl and methylene groups. The spectrum shows a band of $1325-1273 \mathrm{~cm}^{-1}$ corresponding to the vibration of the $\mathrm{C}-\mathrm{N}$ bond from the triphenylamine, and the bands at 753 and $695 \mathrm{~cm}^{-1}$ correspond to the out-ofplane deformation of the $\mathrm{C}-\mathrm{H}$ monosubstituted benzene rings, while the band located at $806 \mathrm{~cm}^{-1}$ can be assigned to the $\mathrm{C}-\mathrm{H}$ bond out-of-plane deformation from the 1,4-disubstituted benzene rings.

\subsection{Optical properties}

Absorption and emission spectra of polymer were recorded for polymers solution in dilute $\mathrm{CHCl}_{3}$ $\left(\sim 10^{-5} \mathrm{M}\right)$ and for thin film made from $\mathrm{CHCl}_{3}$ solution (Figure 5). Absorption spectra for the polymer shows a single absorption band at $306 \mathrm{~nm}$ attributed to $\pi-\pi^{*}$ transitions of the triphenylamine pendant

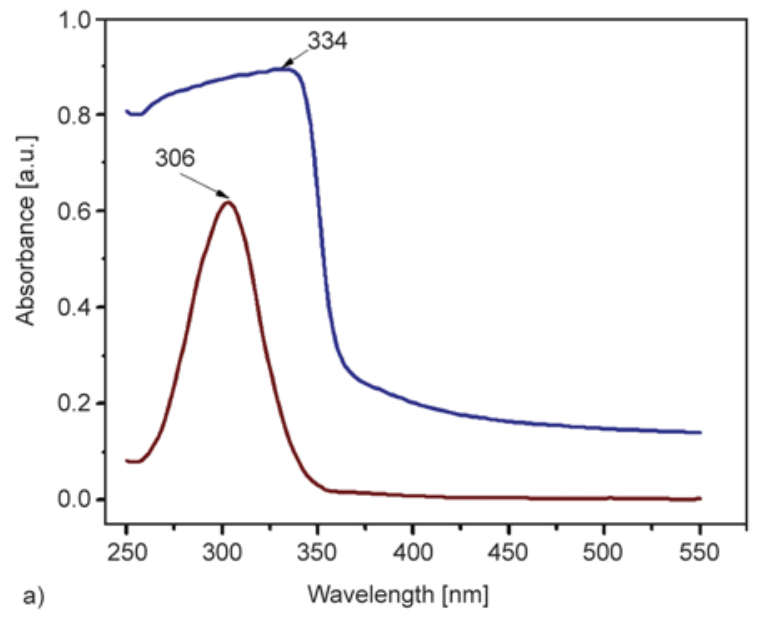

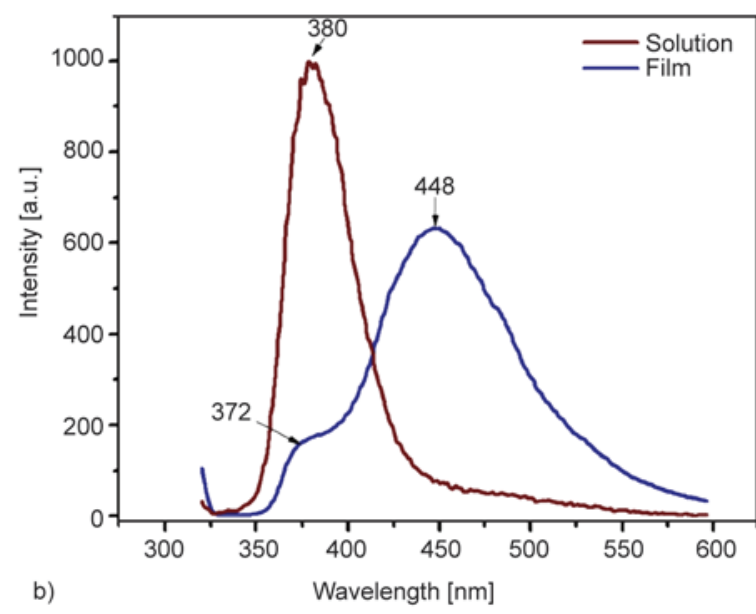

Figure 5. UV-Vis a) and fluorescence b) spectra of polymer recorded at an excitation wavelength of $306 \mathrm{~nm}$. Sample $/ \mathrm{CHCl}_{3}=0.100 \mathrm{mg} / 10 \mathrm{~mL}$. 
moiety. The polymer film cast from $\mathrm{CHCl}_{3}$ exhibit main absorption maximum at $334 \mathrm{~nm}$, which was found to be bathochromically shifted with $28 \mathrm{~nm}$ compared to the absorption of the polymer in solution state. The emission spectrum shows a single emission band at $370 \mathrm{~nm}$ for polymer solution and $448 \mathrm{~nm}$ for film, at an excitation wavelength of $306 \mathrm{~nm}$. An identical red shift phenomenon was also observed for the emission spectra of polymer in solid state compared to polymer solution due to the intermolecular aggregation.

\subsection{Electrochemical behavior}

Electrochemical characteristics of polymer were investigated by running cyclic voltammogram. Thus, polymer (P2) was investigated by recording current intensity vs applied potential curves, for both solution state (using $\mathrm{CH}_{2} \mathrm{Cl}_{2}$ as solvent and $3.5 \cdot 10^{-3} \mathrm{M}$ polymer concentration) and in film deposited on platinum electrode (using acetonitrile/toluene 1:1 solvent mixture). The working electrode potential was swept on the 0.0 to $1.8 \mathrm{~V}$ with $50 \mathrm{mV} \cdot \mathrm{s}^{-1}$ scan rate, for 14 cycles. The multiple cyclic voltammograms of polymer are shown in Figure 6. As it can be seen, in the first scan recorded for the polymer in solution, the voltammogram shows two anodic peaks located at $E_{\mathrm{ox} 1}=0.981 \mathrm{~V}$ and $E_{\mathrm{ox} 2}=1.299 \mathrm{~V}$ and on the reverse scanning, two cathodic peaks located at $E_{\text {red1 }}=0.861 \mathrm{~V}$ and $E_{\text {red2 }}=0.743 \mathrm{~V}$ appeared. The anodic peaks correspond to the oxidation processes of the triphenylamine units from the polymer structure. The first anodic peak is attrib-

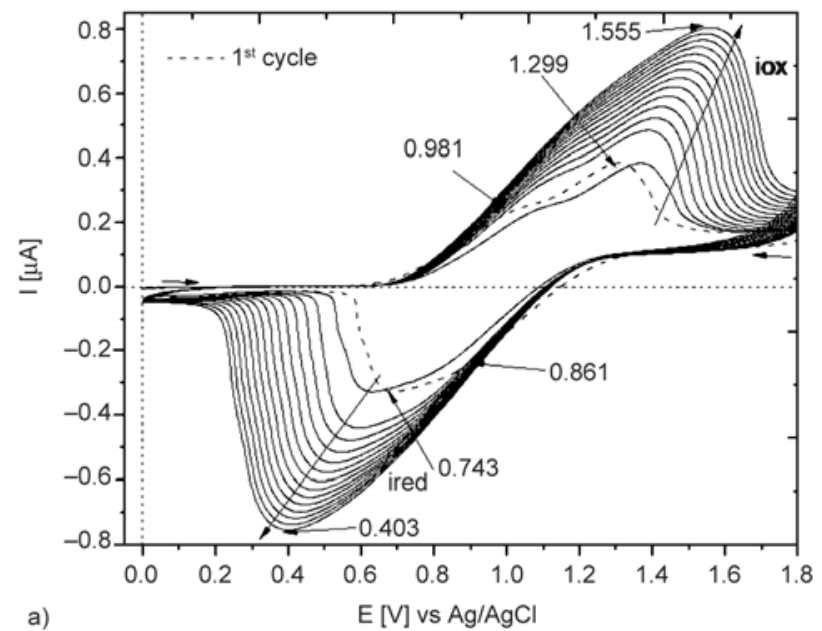

uted to one electron removal from the nitrogen atom of triphenylamine, leading to formation of the radical-cation. Being unstable, chemical coupling processes of the radical cations occurred in the next step with the loss of two protons, leading to neutral tetraphenylbenzidine (TPB) dimer formation [4548]. Starting with the second scan, the peaks current intensities associated with tetraphenylbenzidine oxidation processes increase, while the oxidation peaks are overlapping.

The increase of the current peaks intensities with each running cycle is correlated with the progress of dimerization reaction and formation of a green colored electroactive polymer film on the electrode surface. The shift of the oxidation potential at higher values is due to the increase of the electrical resistance of the polymer film when over-potential was needed to overcome the resistance. The polymer film in the undoped state was washed with $\mathrm{CH}_{2} \mathrm{Cl}_{2}$, removed mechanically, and then was characterized by FT- IR spectroscopy (Figure 7).

The electrochemical behavior of the polymer P2 as thin film deposited on the Pt electrode surface by drop-cast from $\mathrm{CH}_{2} \mathrm{Cl}_{2}$ solution was also investigated. For this, it was recorded the cyclic voltammogram in acetonitrile/toluene (1:1) mixture solution containing $\mathrm{TBABF}_{4}\left(10^{-1} \mathrm{M}\right)$ as supporting electrolyte (Figure 6b). The first cycle shows one large reversible anodic peak located in the 0.852 and $1.446 \mathrm{~V}$, which seems to be composed of two overlapping anodic peaks, corresponding to two successive oxidation processes of triphenylamine units,

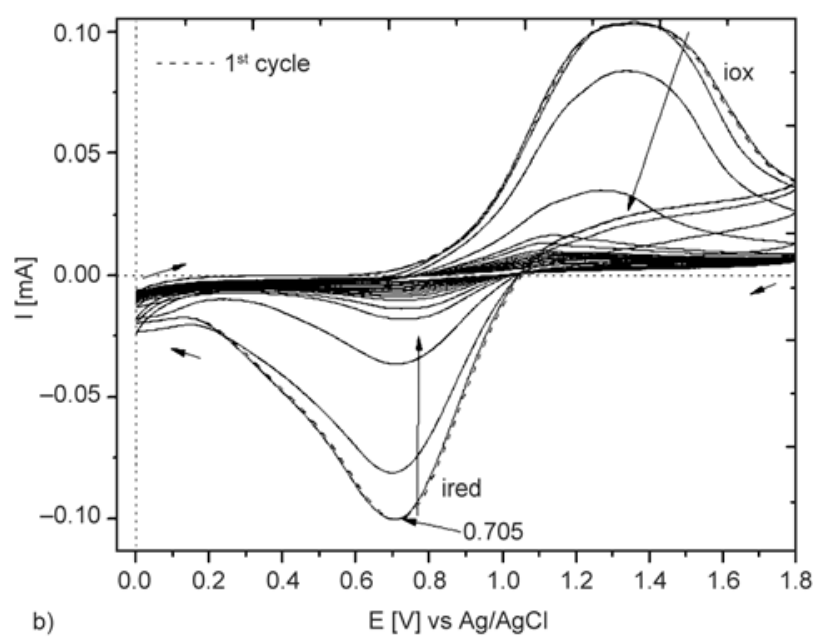

Figure 6. Multiple cyclic voltammograms (14 cycles) recorded for: a) polymer as $\mathrm{CH}_{2} \mathrm{Cl}_{2}$ solution, containing $\mathrm{TBABF}_{4}$ $(0.1 \mathrm{M})$ as supporting electrolyte, using Pt as working electrode (disk, diameter $=1.6 \mathrm{~mm}$ ) and right) b) the polymer film deposited on Pt electrode surface and in acetonitrile/toluene (1:1) solvent mixture containing $\mathrm{TBABF}_{4}$ $(0.1 \mathrm{M})$ as supporting electrolyte; scan rate was $50 \mathrm{mV} \cdot \mathrm{s}^{-1}$ 
Table 2. The electrochemical data of polymer (P2)

\begin{tabular}{|l|c|c|c|c|c|c|}
\hline \multicolumn{1}{|c|}{ Polymer } & $\begin{array}{c}\mathbf{E}_{\text {ox }}{ }^{\text {onset }} \\
{[\mathbf{V}]}\end{array}$ & $\begin{array}{c}\mathbf{E}_{\text {ox1 }} \\
{[\mathbf{V}]}\end{array}$ & $\begin{array}{c}\mathbf{E}_{\text {ox2 }} \\
{[\mathbf{V}]}\end{array}$ & $\begin{array}{c}\mathbf{E}_{\text {red }}{ }^{\text {onset }} \\
{[\mathbf{V}]}\end{array}$ & $\begin{array}{c}\mathbf{E}_{\text {red1 }} \\
{[\mathbf{V}]}\end{array}$ & $\begin{array}{c}\mathbf{E}_{\text {red2 }} \\
{[\mathbf{V}]}\end{array}$ \\
\hline $\mathrm{CH}_{2} \mathrm{Cl}_{2}$-solution & 0.745 & 0.981 & 1.299 & 1.193 & 0.861 & 0.743 \\
\hline Film deposited on Pt & 0.852 & - & 1.336 & 1.059 & - & 0.705 \\
\hline
\end{tabular}

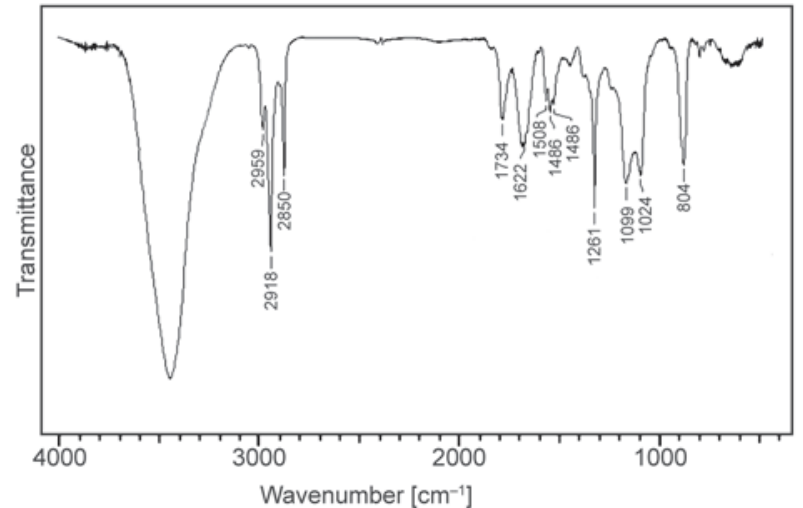

Figure 7. FT-IR spectra $\left(\mathrm{KBr}, \mathrm{cm}^{-1}\right)$ of cross-linked polymer by electropolymerization in solution

while on the reverse scan only one cathodic peak appear at $E_{\text {red }}=0.705 \mathrm{~V}$ which is assigned to reduction process of the oxidized species. The large anodic peak can be due to a more reduced mobility of the electroactive sites in the solid state. At the end of 14 cycles, it was observed that the intensities of anodic and cathodic peaks currents decreased and this can be explained by the fact that during the electropolymerization process the triphenylamine units are consumed forming a cross-linking network. Comparing the onset oxidation potential values from both cases, it can be noted that the polymer is more easily oxidized as $\mathrm{CH}_{2} \mathrm{Cl}_{2}$-solution than as film (Table 2).

By comparing the FT-IR spectra of parent polymer (Figure 4) and cross-linked material (Figure 7) obtained by electropolymerization in solution, some differences can be evidenced:

- the disappearance of the characteristic bands 3059 and $3033 \mathrm{~cm}^{-1}$ assigned to the deformation vibrations of the $(\mathrm{C}-\mathrm{H})$ aromatic;

- the disappearance of the bands at 753 and $695 \mathrm{~cm}^{-1}$ assigned to the deformation vibrations of monosubstituted benzene ring.

\subsection{Electrochromic properties of polymer films}

Depending on the oxidation states, the electrochromic material shows different colors, and usually conjugated electrochromic polymers allow fast color changes when different potentials are applied. The applications of the electrochromic conjugated polymers are quite different due to avantages owned by these materials, because the oxidation states of the polymers are stable and 'resistant over time' [12]. It was observed that the film obtained by electropolymerization of polymer upon transparent ITO electrode surface shows different colors depending on the applied potential. For a more detailed study, insitu UV-Vis spectroelectrochemistry was further employed, using a polymer film deposited on a transparent ITO/glass working electrode and cyclic voltammetry technique coupled with UV-Vis absorbance measurements. This procedure allowed simultaneous recording of the electronic absorption spectra in the range of 300-900 $\mathrm{nm}$ and the current intensity versus applied potential. The experiments were carried out in acetonitrile/toluene (1:1) solvent mixture containing $\mathrm{TBABF}_{4}(0.1 \mathrm{M})$ as supporting electrolyte. Varying the applied potential in range of $0.0-(+1.5) \mathrm{V}$ and then to $0.0 \mathrm{~V}$, the film shows absorption bands in the range of 300-900 nm, which corresponds to the different oxidation states. In the neutral state of polymer (at $0 \mathrm{~V}$ ), the film is transparent in the visible region. By increasing the applied potential value two absorption bands with maxima at 486 and $680 \mathrm{~nm}$, were observed (Figure 8). The intensity of absorption bands increase simultaneously and gradually when the potential values reaches to $1.5 \mathrm{~V}$. During the oxidation process, the polymer film switches its color from colorless, brown, and green to blue, respectively. During the reduction process, the intensities of absorption bands located at 486 and $680 \mathrm{~nm}$, decrease and a third band at $396 \mathrm{~nm}$ can be observed, which is attributed to $\pi-\pi^{*}$ transitions due to expansion of the conjugations (Figure 8).

The potential of the working electrode have been applied to a range of positive values such as 0.0 , 1.0, 1.2, 1.3 and 1.5 $\mathrm{V}$ for 3 minutes (Figure 9), and the polymer switches its color, like in previous case. Spectroelectrochemistry data presented above confirm the presence of the tetraphenylbenzidine (TPB) dimer, which is oxidized at about $0.65 \mathrm{~V}$ forming the $\mathrm{TPB}^{\circ+}$ radical-cations which shows a maximum 

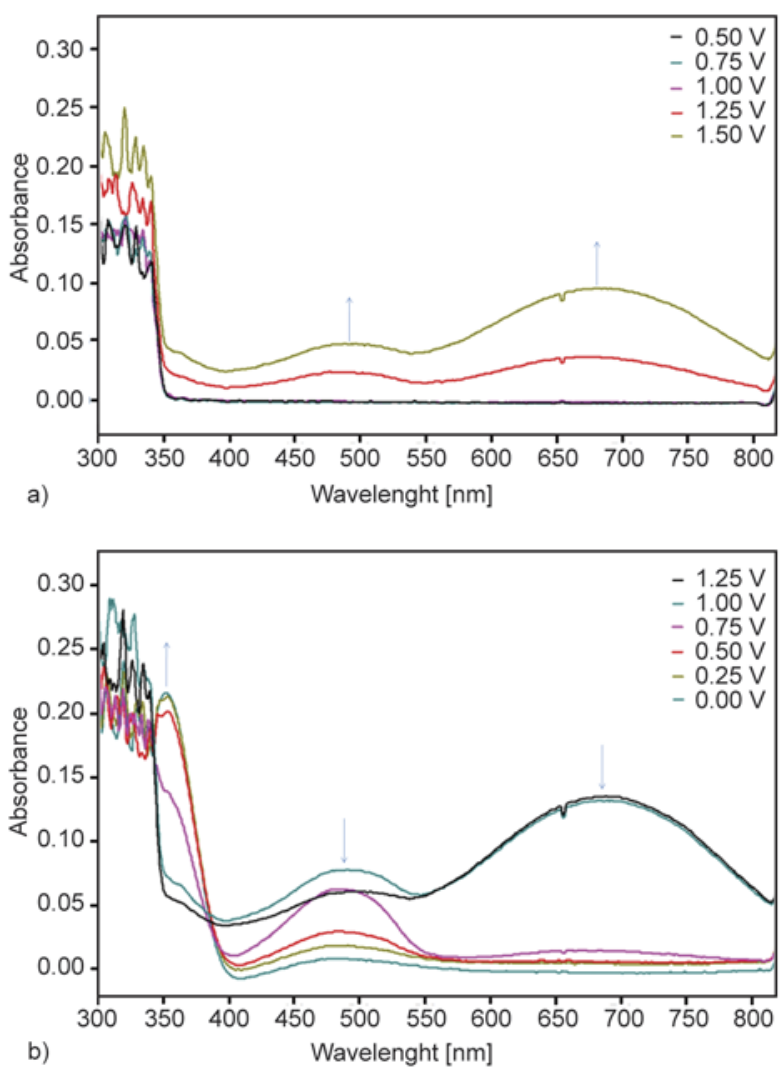

Figure 8. Absorption spectra of $\mathrm{P} 2$ as film deposited on ITO/glass electrode, recorded during the electropolymerization process at different applied potentials: a) during the oxidation and b) during the reduction process

absorption band at $480 \mathrm{~nm}$. The dication formation is observed at potentials more anodic and shows an absorption band at about $678 \mathrm{~nm}$ (Figure 10).
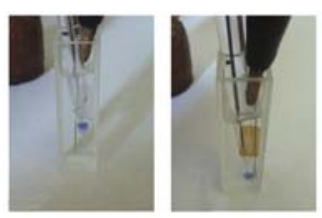

$0.0 \mathrm{~V}$

$1.0 \mathrm{~V}$
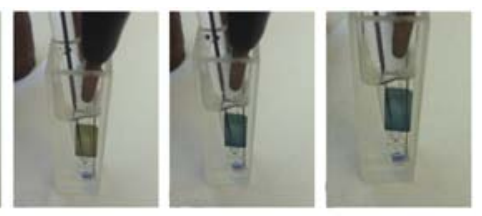

Figure 9. Evolution of the color of the polymer film from neutral to oxidized states

The color switching times were estimated by applying a potentials step and the transmittance profiles were followed. The switching time was defined as the time that was required to reach $95 \%$ of the full change in transmittance after switching potential. The ITO/P2 film oxidation state was switched by stepping the potential between 0.0 and $1.5 \mathrm{~V}$, with time intervals of $15 \mathrm{~s}$ and the current and transmittance at 486 and $680 \mathrm{~nm}$ was monitored versus time. The film color changed from transparent to blue with high contrast of optical transmittance change $(\Delta T$ $\%$ ) of $80 \%$ for $680 \mathrm{~nm}$ and only $29 \%$ for $486 \mathrm{~nm}$. Moreover, the response time of the polymer film was found to be $10 \mathrm{~s}$ at $1.5 \mathrm{~V}$ from color switching and $5 \mathrm{~s}$ for bleaching (Figure 11). The amount of charge $\left(Q_{\mathrm{d}}\right)$ in each current curve for both processes was very similar and reveals a stable anodic electrochemical characteristic of P2 film. On the other hand, coloration efficiency $(\eta)$ of the polymer film at $680 \mathrm{~nm}$ was also calculated to be $670 \mathrm{~cm}^{2} / \mathrm{C}$, using the equation $\eta=\Delta \mathrm{OD} / Q_{\mathrm{d}}=\log \left[T_{\text {neut }} / T_{\text {oxi }}\right] / Q_{\mathrm{d}}\left[\mathrm{cm}^{2} / \mathrm{C}\right]$, where $Q_{\mathrm{d}}$ is the injected charge per unit electrode

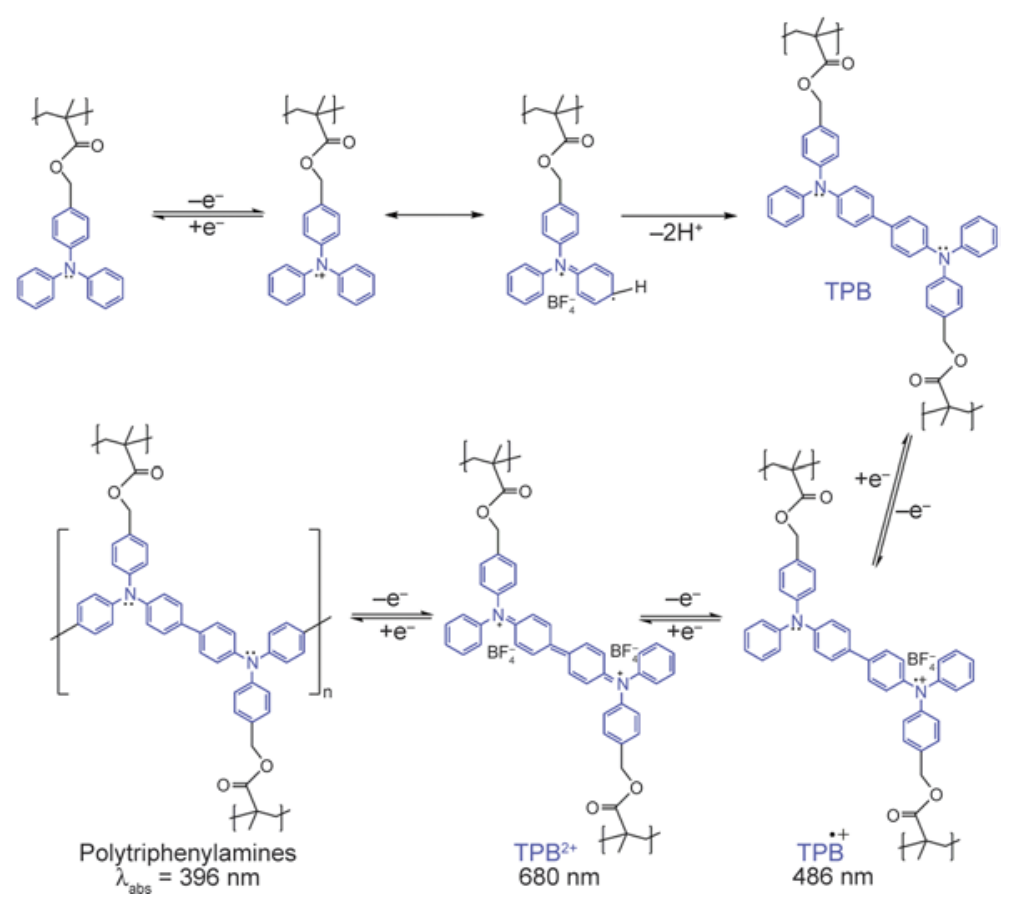

Figure 10. The proposed mechanism for the crosslinking process and the change of color with the applied potential 

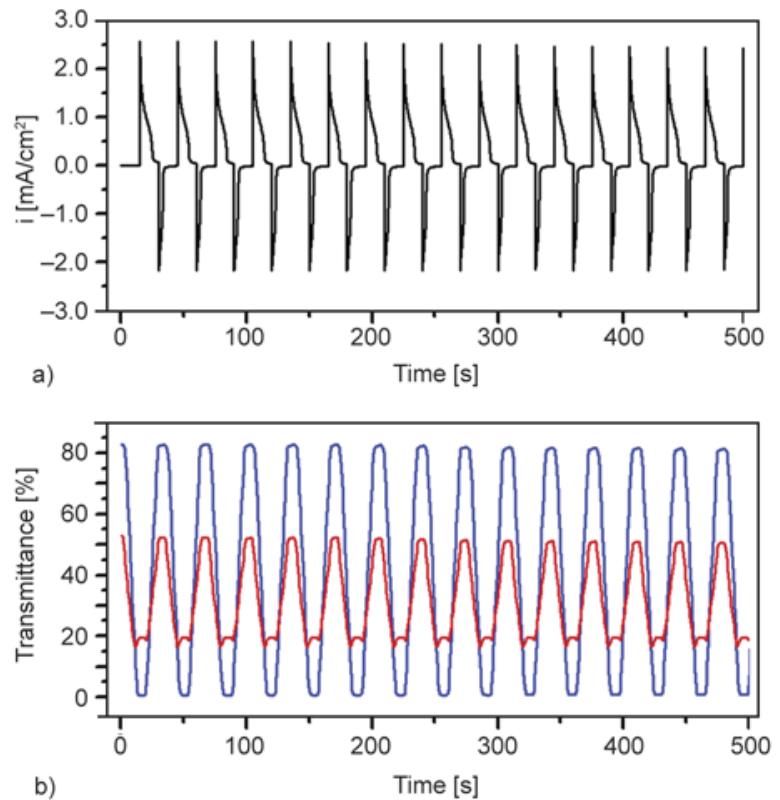

Figure 11. ITO/P2 electrochromic switching between 0 and $1.5 \mathrm{~V}$ (vs $\mathrm{Ag} / \mathrm{AgCl}$ ) applied to the electrodeposited film of $\mathrm{P} 2$ in $\mathrm{CH}_{3} \mathrm{CN} /$ toluene with $0.1 \mathrm{M}$ $\mathrm{TBABF}_{4}$ with a cycle time of $15 \mathrm{~s}$, the current (a) and optical (b) response. Absorption was recorded at $486 \mathrm{~nm}$ (red) and $680 \mathrm{~nm}$ (blue)

area during a redox step, and $T_{\text {neut }}$ and $T_{\text {oxi }}$ are the bleached and colored transmittance values, respectively [13].

After 17 continuous cycles the polymer film exhibited excellent stability of electrochromic characteristics. Considering these results it can be stated that the electropolymerized P2 film can be considered a promising materials for application in optoelectronic devices.
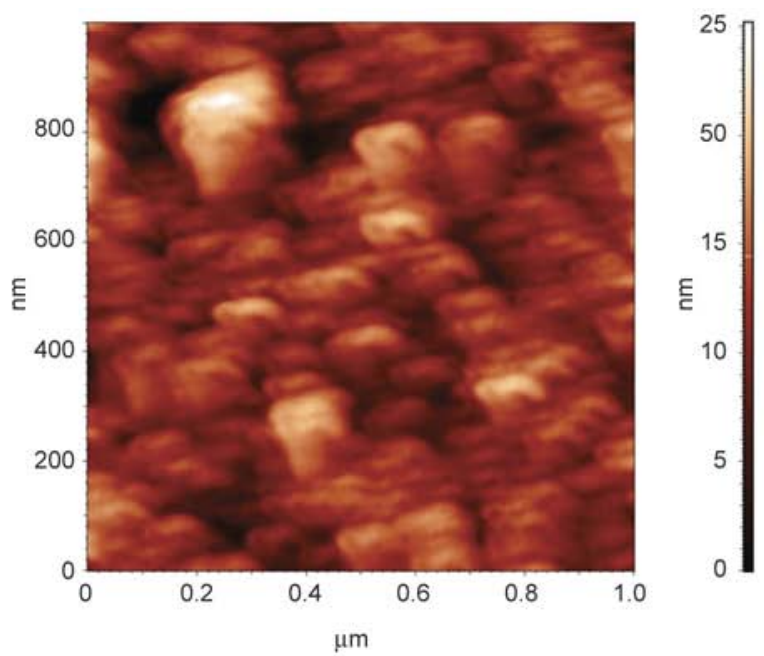

\subsection{Surface morphology of polymer films}

Atomic force microscopy (AFM) investigations were conducted to investigate the surface morphology of the polymer deposited on ITO/glass after electropolymerization. The micrographs recorded show that the film appears smooth and continuous over the whole image, without pinholes or defects and is characterized by morphology consisted of many crowded spheres with a mean diameter of $110 \mathrm{~nm}$ and root mean square (RMS) roughness of $2.75 \mathrm{~nm}$ (Figure 12).

\section{Conclusions}

Polymers based on triphenylamine with well-defined structure and characteristics, were successfully synthesized by atom transfer radical polymerization reactions. The optical properties of poly [4-(diphenylamino)benzyl methacrylate] were investigated by UV-Vis and fluorescence spectroscopy. The electrochemical properties of the synthesized polymers with triphenylamine pendant units were investigated using cyclic voltammetry technique. The synthesized polymers undergo cross-linking processes leading to a conductive film with electrochromic properties and stable color changes with coloration efficiency and high contrast of optical transmittance. The electrochemical cross-linking reaction was possible because the polymers contain in their structure triphenylamine as pendant groups with two free para-positions for direct coupling. The morphology of the resulting film with cross-linked structure was examined by AFM microscopy, the

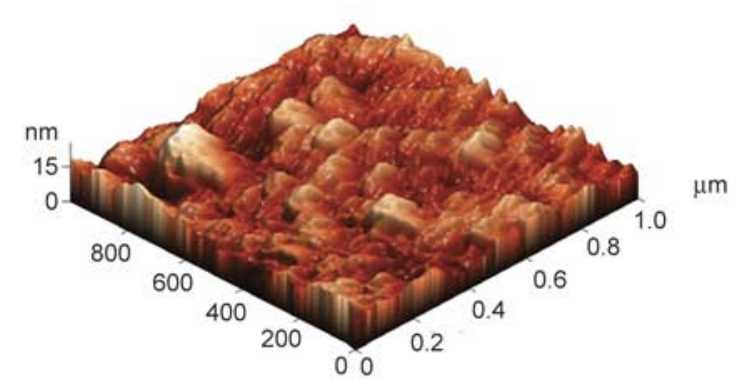

Figure 12. The AFM images of film deposited by electropolymerization process (after 14 scan cycles) 
film appears smooth and continuous without any pinholes or defects being formed from crowded spheres with a mean diameter of $110 \mathrm{~nm}$.

\section{Acknowledgements}

The authors thank to the Romanian National Authority for Scientific Research (UEFISCDI) for financial support (Grant PN-II-ID-PCE-2011-3-0274, Contract 148/2011)

\section{References}

[1] Feast W. J., Peace R. J., Sage I. C., Wood E. L.: Poly (4-vinyltriphenylamine): Synthesis and application as a hole transport layer in light-emitting diodes. Polymer Bulletin, 42, 167-174 (1999). DOI: $10.1007 / \mathrm{s} 002890050449$

[2] Park S-H., Ogino K., Sato H.: Synthesis and characterization of photorefractive polymers with triphenylamine unit and NLO chromophore unit on a side chain. Polymers for Advanced Technologies, 11, 349 358 (2000).

DOI: $10.1002 / 1099-1581(200007) 11: 7<349:: A I D-$ PAT978>3.0.CO;2-Z

[3] Yeh K-M., Lee C-C., Chen Y.: Poly(4-vinyltriphenylamine): Optical, electrochemical properties and its new application as a host material of green phosphorescent $\operatorname{Ir}(\text { ppy })_{3}$ dopant. Synthetic Metals, 158, 565-571 (2008). DOI: 10.1016/j.synthmet.2008.04.001

[4] Iwan A., Sek D.: Polymers with triphenylamine units: Photonic and electroactive materials. Progress in Polymer Science, 36, 1277-1325 (2011). DOI: $10.1016 /$ j.progpolymsci.2011.05.001

[5] Thelakkat M.: Star-shaped, dendrimeric and polymeric triarylamines as photoconductors and hole transport materials for electro-optical applications. Macromolecular Materials and Engineering, 287, 442-461 (2002). DOI: $10.1002 / 1439-2054(20020701) 287: 7<442::$ AIDMAME442>3.0.CO;2-H

[6] Thelakkat R., Hagen J., Haarer D., Schmidt H-W.: Poly(triarylamine)s- synthesis and application in electroluminescent devices and photovoltaics. Synthetic Metals, 102, 1125-1128 (1999).

DOI: $10.1016 / \mathrm{S} 0379-6779(98) 01412-\mathrm{X}$

[7] Forrest S. R.: Ultrathin organic films grown by organic molecular beam deposition and related techniques. Chemical Reviews, 97, 1793-1896 (1997).

DOI: $10.1021 / \mathrm{cr} 9410140$

[8] Zhan X., Zhu D.: Conjugated polymers for high-efficiency organic photovoltaics. Polymer Chemistry, 1, 409-419 (2010).

DOI: $10.1039 / B 9 P Y 00325 \mathrm{H}$

[9] Cheng Y-J., Yang S-H., Hsu C-S.: Synthesis of conjugated polymers for organic solar cell applications. Chemical Reviews, 109, 5868-5923 (2009).

DOI: $10.1021 / \mathrm{cr} 900182 \mathrm{~s}$
[10] Yen H-J., Liou G-S.: Solution-processable triarylamine-based electroactive high performance polymers for anodically electrochromic applications. Polymer Chemistry, 3, 255-264 (2012).

DOI: 10.1039/C1PY00346A

[11] Yen H-J., Liou G-S.: Solution-processable novel nearinfrared electrochromic aromatic polyamides based on electroactive tetraphenyl- $p$-phenylenediamine moieties. Chemistry of Materials, 21, 4062-4070 (2009). DOI: $10.1021 / \mathrm{cm} 9015222$

[12] Mortimer R. J., Dyer A. L., Reynolds J. R.: Electrochromic organic and polymeric materials for display applications. Displays, 27, 2-18 (2006).

DOI: $10.1016 /$ j.displa.2005.03.003

[13] Monk P. M. S., Moritimer R. J., Rosseinsky D. R.: Electrochromism: Fundamentals and applications. VCH, Weinheim (1995).

[14] Lin H-Y., Liou G-S.: Poly(triphenylamine)s derived from oxidative coupling reaction: Substituent effects on the polymerization, electrochemical, and electrooptical properties. Journal of Polymer Science Part A: Polymer Chemistry, 47, 285-294 (2009).

DOI: $10.1002 /$ pola.23155

[15] Grazulevicius J. V., Strohriegl P., Pielichowski J., Pielichowski K.: Carbazole-containing polymers: Synthesis, properties and applications. Progress in Polymer Science, 28, 1297-1353 (2003). DOI: 10.1016/S0079-6700(03)00036-4

[16] Mori H., Ookuma H., Endo T.: Poly( $N$-vinylcarbazole) star polymers and amphiphilic star block copolymers by xanthate-mediated controlled radical polymerization. Macromolecules, 41, 6925-6934 (2008).

DOI: $10.1021 / \mathrm{ma} 801266 \mathrm{~h}$

[17] Keddie D. J., Guerrero-Sanchez C., Moad G.: The reactivity of $\mathrm{N}$-vinylcarbazole in RAFT polymerization: Trithiocarbonates deliver optimal control for the synthesis of homopolymers and block copolymers. Polymer Chemistry, 4, 3591-3601 (2013). DOI: $10.1039 / \mathrm{C} 3 \mathrm{PY} 00487 \mathrm{~B}$

[18] Mori H., Ookuma H., Nakano S., Endo T.: Xanthatemediated controlled radical polymerization of $N$-vinylcarbazole. Macromolecular Chemistry and Physics, 207, 1005-1017 (2006). DOI: $10.1002 / \mathrm{macp} .200600070$

[19] Grigoras M., Negru O. I.: Synthesis of star $\operatorname{poly}(N-$ vinylcarbazole) by microwave-assisted reversible addition-fragmentation chain transfer polymerization (RAFT). Polymers, 4, 1183-1194 (2012).

DOI: $10.3390 /$ polym 4021183

[20] Nakabayashi K., Mori H.: Novel complex polymers with carbazole functionality by controlled radical polymerization. International Journal of Polymer Science, 2012, 170912/1-170912/18 (2012).

DOI: $10.1155 / 2012 / 170912$

[21] Nakabayashi K., Mori H.: Recent progress in controlled radical polymerization of $N$-vinyl monomers. European Polymer Journal, 49, 2808-2838 (2013). DOI: $10.1016 /$ j.eurpolymj.2013.07.006 
[22] Baethge H., Butz S., Schmidt-Naake G.: 'Living' free radical copolymerization of styrene and $\mathrm{N}$-vinylcarbazole. Macromolecular Rapid Communications, 18, 911-916 (1997) DOI: $10.1002 /$ marc.1997.030181003

[23] Hua J., Chen D., Yu Y., Xu L., Zhang Y., Jing X., Wu A., Shi L.: Preparation of C60 bonded poly(N-vinylcarbazole) with $\mathrm{C} 60 \mathrm{Cln} / \mathrm{CuCl} / \mathrm{Bpy}$ catalyst system. Polymer Bulletin, 48, 135-141 (2002).

DOI: $10.1007 / \mathrm{s} 00289-002-0023-1$

[24] Hua J., Chen D., Jing X., Xu L., Yu Y., Zhang Y.: Preparation and photoconducting property of $\mathrm{C}_{60} \mathrm{C}_{\mathrm{ln}-\mathrm{m}}{ }^{-}$ bonded poly(N-vinylcarbazole) with $\mathrm{C}_{60} \mathrm{Cl}_{\mathrm{n}} / \mathrm{CuCl} /$ Bpy catalyst system. Journal of Applied Polymer Science, 87, 606-609 (2003).

DOI: $10.1002 /$ app. 11320

[25] Behl M., Hattemer E., Brehmer M., Zentel R.: Tailored semiconducting polymers: Living radical Polymerization and NLO-functionalization of triphenylamines. Macromolecular Chemistry and Physics, 203, 503510 (2002).

DOI: 10.1002/1521-3935(20020201)203:3<503::AIDMACP503>3.0.CO;2-P

[26] Lindner S. M., Thelakkat M.: Fluorescent dye-labeled polymers carrying triphenylamine, styrene, or acrylate pendant groups. Macromolecular Chemistry and Physics, 207, 2084-2092 (2006).

DOI: $10.1002 /$ macp. 200600385

[27] Lindner S. M., Kaufmann N., Thelakkat M.: Nanostructured semiconductor block copolymers: $\pi-\pi$ stacking, optical and electrochemical properties. Organic Electronics, 8, 69-75 (2007).

DOI: $10.1016 /$ j.orgel.2006.11.002

[28] Schroot R., Friebe C., Altuntas E., Crotty S., Jäger M., Schubert U. S.: Nitroxide-mediated polymerization of styrenic triarylamines and chain-end functionalization with a ruthenium complex: Toward tailored photoredoxactive architectures. Macromolecules, 46, 2039-2048 (2013).

DOI: $10.1021 / \mathrm{ma3} 02631 \mathrm{f}$

[29] Häussler M., Phei Lok Y., Chen M., Jasieniak J., Adhikari R., King S. P., Haque S. A., Forsyth C. M., Winzenberg K., Watkins S. E., Rizzardo E., Wilson G. J.: Benzothiadiazole-containing pendant polymers prepared by RAFT and their electro-optical properties. Macromolecules, 43, 7101-7110 (2010).

DOI: $10.1021 / \mathrm{ma1} 008572$

[30] Williams P. E., Moughton A. O., Patterson J. P., Khodabakhsh S., O'Reilly R. K.: Exploring RAFT polymerization for the synthesis of bipolar diblock copolymers and their supramolecular self-assembly. Polymer Chemistry, 2, 720-729 (2011).

DOI: $10.1039 /$ COPY00359J
[31] zur Borg L., Domanski A. L., Breivogel A., Bürger M., Berger R., Heinze K., Zentel R.: Light-induced charge separation in a donor-chromophore-acceptor nanocomposite poly[TPA-Ru(tpy $)_{2}$ @@ZnO. Journal of Materials Chemistry C, 1, 1223-1230 (2013). DOI: 10.1039/C2TC00535B

[32] zur Borg L., Lee D., Lim J., Bae W. K., Park M., Lee S., Lee C., Char K., Zentel R.: The effect of band gap alignment on the hole transport from semiconducting block copolymers to quantum dots. Journal of Materials Chemistry C, 1, 1722-1726 (2013). DOI: $10.1039 / \mathrm{C} 3 \mathrm{TC} 00837 \mathrm{~A}$

[33] Tew G. N., Pralle M. U., Stupp S. I.: Supramolecular materials with electroactive chemical functions. Angewandte Chemie International Edition, 39, 517-521 (2000).

DOI: 10.1002/(SICI)1521-3773(20000204)39:3<517:: AID-ANIE517>3.0.CO;2-\#

[34] Natori I., Natori S., Usui H., Sato H.: Anionic polymerization of 4-diphenylaminostyrene: Characteristics of the alkyllithium $/ N, N, N^{\prime}, N^{\prime}$-tetramethylethylenediamine system for living anionic polymerization. Macromolecules, 41, 3852-3858 (2008).

DOI: $10.1021 / \mathrm{ma} 800222 \mathrm{z}$

[35] Natori I., Natori S., Sekikawa H., Ogino K.: Synthesis of $\mathrm{C}_{60}$ end-capped poly(4-diphenylaminostyrene): Addition of poly(4-diphenylaminostyryl)lithium to $\mathrm{C}_{60}$. Reactive and Functional Polymers, 69, 613-618 (2009). DOI: $10.1016 /$ j.reactfunctpolym.2009.04.003

[36] Higashihara T., Ueda M.: Living anionic polymerization of 4-vinyltriphenylamine for synthesis of novel block copolymers containing low-polydisperse poly(4vinyltriphenylamine) and regioregular poly(3-hexylthiophene) segments. Macromolecules, 42, 8794-8800 (2009).

DOI: $10.1021 / \mathrm{ma901636a}$

[37] Natori I., Natori S., Sekikawa H., Takahashi T., Ogino K., Tsuchiya K., Sato H.: Poly(4-diphenylaminostyrene) with a well-defined polymer chain structure: Controllable optical and electrical properties. Polymer, 51, 1501-1506 (2010).

DOI: $10.1016 /$ j.polymer.2010.01.054

[38] Natori I., Natori S., Sekikawa H., Takahashi T., Sato H.: Bipolar polymer semiconductor blends of $\mathrm{C}_{60}$-endcapped poly(4-diphenylaminostyrene) and poly(4diphenylaminostyrene): One-pot synthesis and chargetransport properties. Journal of Applied Polymer Science, 121, 3433-3438 (2011).

DOI: $10.1002 / a p p .33864$

[39] Natori I., Natori S., Sekikawa H., Tsuchiya K., Ogino K.: Synthesis of poly( $p$-phenylene)-poly(4-diphenylaminostyrene) bipolar block copolymers with a wellcontrolled and defined polymer chain structure. Journal of Polymer Science Part A: Polymer Chemistry, 49, 1655-1663 (2011). DOI: $10.1002 /$ pola. 24590 
[40] Natori I., Natori S., Tsuchiya K., Ogino K.: Synthesis of novel semiconducting polymers consisting of $p$ phenylene, $p$-phenylenevinylene, and styrylamine structures: Copolymerization and dehydrogenation of 1,3cyclohexadiene and 4-diphenylaminostyrene. Macromolecules, 44, 256-262 (2011).

DOI: $10.1021 / \mathrm{ma1} 02183 \mathrm{f}$

[41] Hsu J-C., Chen Y., Kakuchi T., Chen W-C.: Synthesis of linear and star-shaped poly[4-(diphenylamino)benzyl methacrylate]s by group transfer polymerization and their electrical memory device applications. Macromolecules, 44, 5168-5177 (2011).

DOI: $10.1021 / \mathrm{ma} 2006377$

[42] Negru O. I., Grigoras M.: Grafted polytriphenylamines synthesized by atom transfer radical polymerization in tandem with oxidative polycondensation. Iranian Polymer Journal, 22, 641-651 (2013). DOI: $10.1007 / \mathrm{s} 13726-013-0163-1$

[43] Negru O. I., Grigoras M.: Polytriphenylamines synthesized by interfacial and microemulsion oxidative polymerization. Colloid and Polymer Science, 292, 143151 (2014).

DOI: $10.1007 / \mathrm{s} 00396-013-3055-1$
[44] Stolka M., Pai D. M., Renfer D. S., Yanus J. F.: Photoconductivity and hole transport in polymers of aromatic amine-containing methacrylates. Journal of Polymer Science: Polymer Chemistry Edition, 21, 969-983 (1983)

DOI: $10.1002 /$ pol.1983.170210406

[45] Seo E. T., Nelson R. F., Fritsch J. M., Marcoux L. S., Leedy D. W., Adams R. N.: Anodic oxidation pathways of aromatic amines. Electrochemical and electron paramagnetic resonance studies. Journal of the American Chemical Society, 88, 3498-3503 (1966).

DOI: $10.1021 / \mathrm{ja} 00967 \mathrm{a} 006$

[46] Petr A., Kvarström C., Dunsch L., Ivaska A.: Electrochemical synthesis of electroactive polytriphenylamine. Synthetic Metals, 108, 245-247 (2000). DOI: 10.1016/S0379-6779(99)00137-X

[47] Chiu K. Y., Su T. X., Li J. H., Lin T-H., Liou G-S., Cheng S-H.: Novel trends of electrochemical oxidation of amino-substituted triphenylamine derivatives. Journal of Electroanalytical Chemistry, 575, 95-101 (2005). DOI: 10.1016/j.jelechem.2004.09.005

[48] Oyama M., Nozaki K., Okazaki S.: Pulse-electrolysis stopped-flow method for the electrospectroscopic analysis of short-lived intermediates generated in the electrooxidation of triphenylamine. Analytical Chemistry, 63, 1387-1392 (1991). DOI: $10.1021 / \mathrm{ac} 00014 \mathrm{a} 010$ 